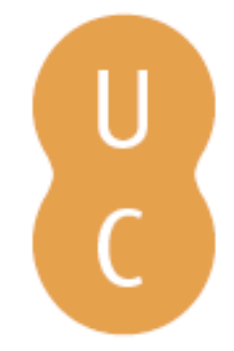

\title{
nommalina
}

\section{Modelação da distribuição espaço-temporal da população da área metropolitana de Lisboa com recurso a parâmetros empíricos}

Autor(es): $\quad$ Freire, Sérgio

Publicado por: Imprensa da Universidade de Coimbra

URL

persistente: URI:http://hdl.handle.net/10316.2/31179

DOI: $\quad$ DOI:http://dx.doi.org/10.14195/978-989-26-0244-8_81

Accessed : $\quad$ 26-Apr-2023 12:11:41

A navegação consulta e descarregamento dos títulos inseridos nas Bibliotecas Digitais UC Digitalis, UC Pombalina e UC Impactum, pressupõem a aceitação plena e sem reservas dos Termos e Condições de Uso destas Bibliotecas Digitais, disponíveis em https://digitalis.uc.pt/pt-pt/termos.

Conforme exposto nos referidos Termos e Condições de Uso, o descarregamento de títulos de acesso restrito requer uma licença válida de autorização devendo o utilizador aceder ao(s) documento(s) a partir de um endereço de IP da instituição detentora da supramencionada licença.

Ao utilizador é apenas permitido o descarregamento para uso pessoal, pelo que o emprego do(s) título(s) descarregado(s) para outro fim, designadamente comercial, carece de autorização do respetivo autor ou editor da obra.

Na medida em que todas as obras da UC Digitalis se encontram protegidas pelo Código do Direito de Autor e Direitos Conexos e demais legislação aplicável, toda a cópia, parcial ou total, deste documento, nos casos em que é legalmente admitida, deverá conter ou fazer-se acompanhar por este aviso.

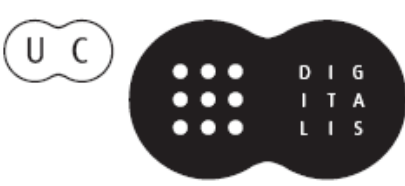




\section{TRUNFOS DE UMA}

\section{EOGRAFIA ACIVA}

\section{DESENVOLVIMENTO LOCAL,}

AMBIENTE,

ORDENAMENTO

E TECNOLOGIA

Norberto Santos

Lúcio Cunha

COORDENAÇÃO 
Sérgio Freire

e-GEO, Centro de Estudos de Geografia e Planeamento Regional, FCSH

Universidade Nova de Lisboa

\section{MODELAÇÃO DA DISTRIBUIÇÃO ESPAÇO-TEMPORAL DA POPULAÇÃO DA ÁREA METROPOLITANA DE LISBOA COM RECURSO A PARÂMETROS EMPÍRICOS}

\section{INTRODUÇÃO}

Informação cartográfica detalhada e actual sobre a distribuição da população no espaço e no tempo é essencial para suporte à tomada de decisão numa variedade de domínios, nomeadamente em protecção civil, geomarketing, planeamento e ordenamento do território, estudos ambientais, de saúde, e em defesa e segurança nacional. De facto tais dados podem ser úteis em praticamente todas as aplicaçóes que envolvam a distribuição geográfica da população, se forem produzidos a escalas espaciais e temporais apropriadas (Sutton et al., 2003). A espacialização destes dados num formato matricial aumenta significativamente a sua utilidade e facilita a sua integração com outros dados espaciais para análise ou modelação (Deichmann et al., 2001).

De entre as diversas abordagens que têm sido seguidas para estimar a distribuição espacial de um quantitativo populacional, o mapeamento dasimétrico permite limitar a distribuição da variável às áreas em que de facto está presente através da utilização de dados auxiliares que com esta estejam relacionados, no processo de interpolação zonal. Em Portugal, Néry et al. (2007) demonstraram a utilidade destes métodos na desagregação espacial de dados censitários, e que esta melhora com a utilização de informação auxiliar sobre uso e ocupação do solo.

Adicionalmente, a população não é estática, sendo a sua variação temporal significativa para a maioria das aplicaçôes práticas: numa dada área, a quantidade e/ou distribuição da população no período diurno normalmente difere substancialmente da verificada no período nocturno devido às deslocaçóes induzidas pelas actividades humanas, como trabalho, estudo e lazer. Porém, os recenseamentos populacionais apenas registam com rigor o local de residência e pernoita habitual da populaçáo, que disponibilizam de forma agregada para uma zona de dimensão variável.

Uma forma bem sucedida de incorporar a dimensão temporal na distribuição da população é através da estimação probabilística de "população ambiente" em vez da população "residencial". Dobson et al. (2000), no contexto do LandScan, propuseram o conceito de "população ambiente" como uma média temporal da densidade populacional que tem em consideração as actividades humanas. Porém, esta métrica constitui um compromisso entre distribuiçóes diurna e nocturna que em rigor não representa nenhuma destas. Assim, foi reconhecida a necessidade de dados que possuam resolução espacial e temporal acrescidas 
(Dobson, 2002), pelo que a mesma equipa está a desenvolver superfícies diurnas e nocturnas de população para os EUA com resolução de 3 segundos de arco (cerca de $90 \mathrm{~m}$ ) - o LandScan USA (Bhaduri et al., 2002). Com vista a melhorar a estimação da população exposta em situaçôes de emergência, o Laboratório Nacional de Los Alamos (EUA) combinou vários tipos de dados existentes para modelar as distribuiçóes diurnas e nocturnas da população desse país com uma resolução de 250 metros (McPherson e Brown, 2003). Em Portugal esta abordagem foi adaptada para se cartografar a distribuição da população de dia e de noite nos concelhos de Cascais e Oeiras, com 25 m de resolução (Freire, 2007; 2008; 2009).

O presente trabalho teve por objectivos o aperfeiçoamento e teste de uma metodologia para cartografar as distribuiçóes diurnas e nocturnas da população na AML com alta resoluçáo espacial, de forma a permitir análises à escala local.

\section{METODOLOGIA}

\section{1. Área de estudo}

Os dezoito concelhos da Área Metropolitana de Lisboa (AML), definidos com base nos limites administrativos oficiais de 2001, constituem a área deste estudo (Figura 1).

Figura 1 - Localização e configuração da área de estudo.

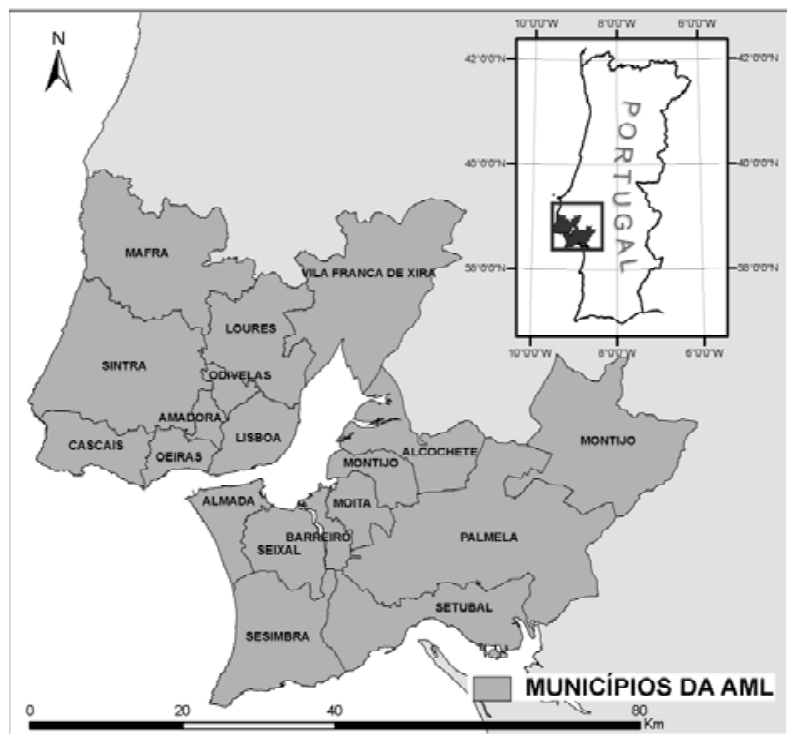

A AML é a principal área metropolitana de Portugal, sendo responsável por 36\% do PIB e tendo $30 \%$ das empresas nacionais aí localizadas. A regiáo ocupa uma superfície de $2963 \mathrm{~km}^{2}$ e tem uma população total residente de 2.661 .850 habitantes, $26 \%$ da população do país (INE, 2001). Apesar da densidade populacional média ser 898 habitantes/ 
$/ \mathrm{km}^{2}$, esta varia significativamente no espaço e no tempo. Para além das zonas fortemente urbanizadas, a regiấo inclui vastas áreas rurais com povoamento disperso cuja desigual densidade populacional não é adequadamente capturada e representada pelas zonas censitárias, que podem ter grande dimensão mesmo ao nível da subsecção estatística. Para além disso, devido aos movimentos pendulares efectuados por razóes de trabalho ou estudo, a população diurna de concelhos na área de estudo chega a diferir em mais de 50\% dos valores censitários (INE, 2003).

As características da área de estudo e a disponibilidade de informação geográfica e estatística propiciam um contexto apropriado para o presente trabalho.

\subsection{Dados}

Os dados usados no presente estudo foram de três tipos principais (Tabela 1): a) dados fisiográficos (arruamentos, ocupação e uso do solo), b) informação censitária e estatística (censos, movimentos pendulares) e c) superfície de distribuição diurna da população de Cascais e Oeiras. A informação estatística mais recente (2001) fornece os quantitativos populacionais a serem espacializados, enquanto os restantes dados permitem definir as unidades espaciais e parâmetros usados para desagregar os valores dos Censos.

Tabela 1 - Nomenclatura de uso de ocupação do solo de interesse municipal.

\begin{tabular}{|l|c|c|}
\hline \multicolumn{1}{|c|}{ Dados } & Data & Tipo \\
\hline Eixos de via & 2004 & Vectorial \\
\hline LULC (COS90; CLC2000) & $1990 ; 2000$ & Vectorial \\
\hline Seç̧óes estatísticas & 2001 & Vectorial \\
\hline População residente censo & 2001 & Base de dados \\
\hline Movimentos pendulares & 2001 & Matriz O/D concelhia \\
\hline População diurna DemoCarto & 2001 & Matricial (25m) \\
\hline
\end{tabular}

\subsection{Modelação}

O processamento de dados e modelação foi realizado com recurso a um Sistema de Informação Geográfica, o ArcGIS 9.3 (ESRI ${ }^{\odot}$ ). As principais tarefas envolvidas na modelação são sintetizadas no fluxograma da Figura 2. Na figura, dados de entrada estão assinalados a cinzento claro, produtos intermédios ou sub-produtos a cinzento mais escuro, e resultados principais a cinzento-escuro e a negrito.

A modelação da distribuição da população assenta em mapeamento dasimétrico matricial usando os eixos de via, caracterizados funcionalmente, para re-distribuir a população. A abordagem é baseada em McPherson e Brown (2003) com modificaçóes e adaptaçóes. Para os municipios da AML foram geradas quatro superficies matriciais de densidade populacional: população (residencial) nocturna, população diurna residencial, população diurna deslocada nos locais de trabalho ou estudo, e população diurna total. A abordagem geral foi testada e apresentada previamente para os municipios de Cascais e Oeiras, inte- 
grantes da AML (Freire, 2007). No entanto, devido à sua morosidade e custo, a metodologia original foi adaptada e melhorada para tornar viável a modelação de toda a AML, nomeadamente através da introdução de amostragem empírica e "mapeamento dasimétrico inteligente" (Mennis e Hultgren, 2006).

Figura 2 - Modelo usado para estimar a distribuição da população.

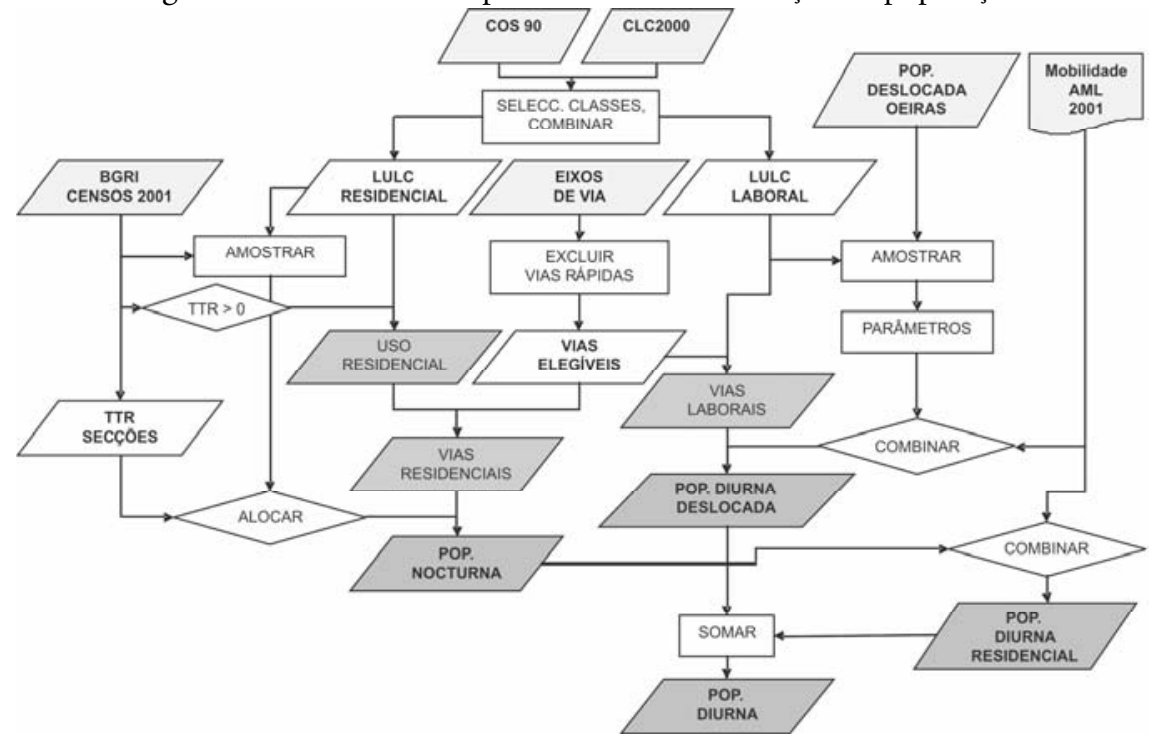

A distribuição nocturna (residencial) foi obtida através da re-distribuição da população residente das secçóes censitárias (zonas de origem) para as vias consideradas residenciais (zonas de destino). Primeiro, dos mapas de uso e ocupação do solo foram seleccionadas e combinadas classes relevantes de forma a identificar-se zonas com verdadeira função residencial. De forma a minimizar erros e limitações da cartografia, foram aplicadas algumas regras como excluir sub-secçóes sem população residente. Duas classes residenciais foram consideradas para definir duas densidades populacionais: 'Tecido Urbano Contínuo' e 'Tecido Urbano Descontínuo'. Para definir a densidade média geral de cada classe, estas foram amostradas usando a população residente por sub-secção estatística, através do método da inclusão total (Mennis e Hultgren, 2006). Seguidamente, vias rápidas foram excluídas e as vias elegíveis assim resultantes foram intersectadas com uso do solo residencial de forma a definirem-se as vias residenciais. Estas foram rasterizadas a $25 \mathrm{~m}$ e a populaçáo residente das secçôes censitárias foi interpolada para as células residenciais de acordo com a respectiva fracção de densidade, ponderada pela área de cada classe.

A distribuição diurna da população resulta da soma de duas superfícies matriciais: (1) população diurna deslocada nos locais de trabalho ou estudo, e (2) a população diurna residencial. Esta última foi obtida através da multiplicação da distribuição nocturna pela percentagem da população residente que, de acordo com as estatísticas de mobilidade disponíveis (INE, 2003), não se desloca regularmente para o local de trabalho ou estudo. A grid de população diurna deslocada obteve-se através da alocação do total de população deslocada 
em cada concelho para vias consideradas 'laborais', de forma análoga à usada para modelar a distribuição nocturna. A partir da cartografia de usos e ocupação do solo e aplicação de regras, duas classes de uso 'laboral' foram definidas: uma correspondendo a áreas exclusivamente industriais, comerciais, e de serviços (públicos ou privados), e outra 'mista', de tipologia predominantemente residencial mas com presença de actividades comerciais ou serviços. De forma a obter a densidade populacional média da classe, estas classes foram amostradas usando a superfície detalhada de população deslocada que foi previamente gerada para Cascais, com resoluçáo de 25 m (ver Freire, 2007).

\section{RESUlTADOS}

As grids com resolução de $25 \mathrm{~m}$ foram agregadas para $50 \mathrm{~m}$ para fins de visualização e utilização, sendo assim os resultados constituídos por superfícies matriciais com densidades populacionais por célula com $2500 \mathrm{~m}^{2}$ (0,25 ha) de área (Figura 3).

Figura 3 - Amostra de resultados centrada no concelho de Lisboa:

(A) população nocturna e (B) população diurna.

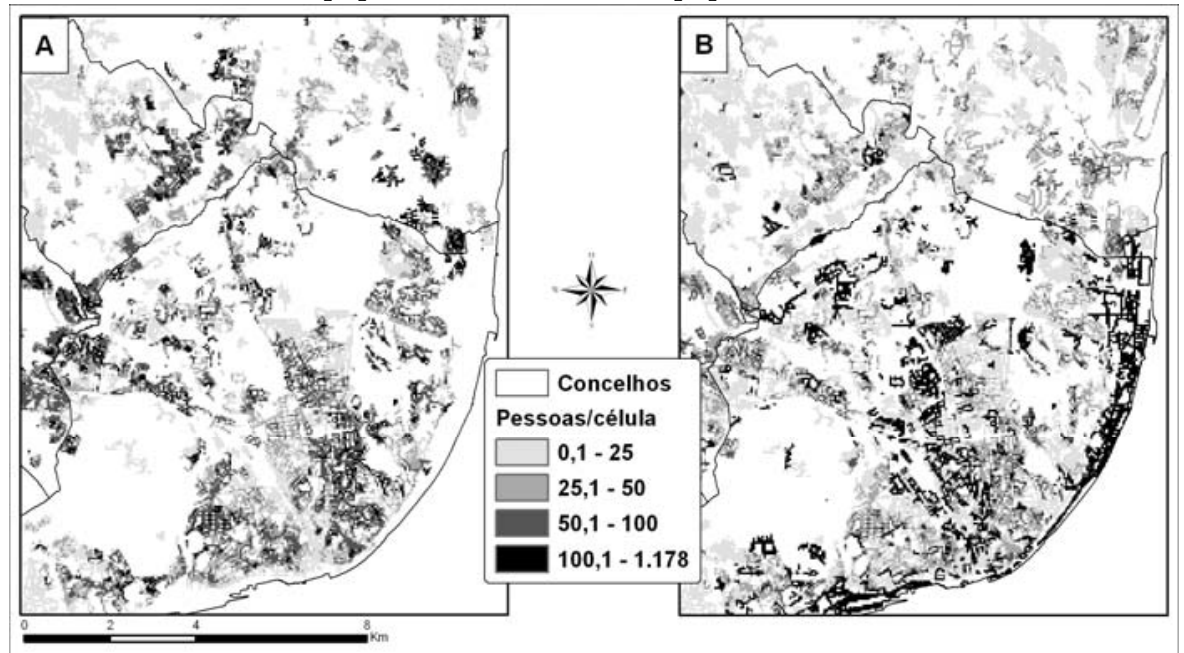

As distribuiçóes nocturna e diurna representam aproximadamente a densidade máxima num dia útil, assumindo que de noite toda a população está nas suas residências, e que no período diurno toda a população trabalhadora e estudante está presente nos locais de trabalho e estudo, e a remanescente na sua residência. Esta situação constitui uma simplificação da realidade, mas mesmo assim preferível a uma simples média zonal da população residente por polígono censitário.

Procedimentos de validação e avaliação da qualidade dos resultados foram efectuados para as distribuiçóes populacionais nocturna, e diurna deslocada. A distribuição nocturna foi validada usando todas as sub-secçóes estatísticas como referência, comparando a sua população residente com a estimada pelo modelo, numa análise de correlação. Obteve-se 
um coeficiente de correlação (r) de 0,85. Avaliação da distribuição diurna deslocada foi limitada pela ausência de dados de referência independentes e com maior resolução distribuídos por toda a área de estudo. Assim, a validação foi feita apenas para Oeiras usando a superfície detalhada de população deslocada já existente para esse concelho como referência, definindo uma grelha de $500 \mathrm{~m}$ e amostrando aleatóriamente $50 \%$ dos sectores. Da análise de correlação resultou um coeficiente (r) de 0,6.

A superfície de distribuição populacional nocturna apresenta resolução superior aos dados censitários, enquanto a distribuição diurna era previamente inexistente. As distribuiçóes nocturna e diurna podem ainda ser combinadas através de uma média ponderada de forma a obter-se uma superfície de 'populaçáo ambiente', representando uma média temporal da densidade populacional que tem em consideraçáo as principais actividades humanas - repouso, trabalho e estudo.

\section{CONCLUSŌES}

A abordagem implementada permite modelar distribuiçóes nocturnas e diurnas da população na Área Metropolitana de Lisboa com elevada resolução espacial, permitindo melhorar a análise ao nível local para múltiplos fins. Ambas as superfícies são espacialmente compatíveis e comparáveis (i.e., cálculo da variação noite-dia). São ainda estimadas as distribuiçôes da população deslocada e residencial no período diurno, sendo preservados no modelo os quantitativos populacionais oficiais para cada concelho.

Estes resultados podem ser úteis numa variedade de estudos envolvendo população, nomeadamente em protecção civil (ver Freire, 2008; 2009), análise de transportes, ambiente e planeamento, saúde (Freire, 2007) e geomarketing. Como exemplo, a distribuição de população diurna pode ser agregada por Freguesia para ser considerada no planeamento da localização e capacidade de equipamentos públicos, como creches e centros de saúde.

Futuras versóes beneficiariam da utilização de cartografia de uso e ocupação do solo mais actualizada e detalhada quanto à caracterização funcional, bem como de incorporaçáo de estatísticas de movimentos pendulares mais desagregados do que o nível do concelho. Seria ainda importante produzir segmentaçóes temporais acrescidas (e.g., dentro do ciclo diário ou variaçóes sazonais).

\section{REFERÊNCIAS BIBLIOGRÁFICAS}

Bhaduri, B., E. Bright, P. Coleman, J. Dobson 2002. LandScan: Locating People is What Matters. Geoinformatics, Vol. 5, No. 2, Págs. 34-37.

Deichmann, U., Balk, D., Yetman, G., 2001, Transforming Population Data for Interdisciplinary Usages: From Census to Grid. NASA Socioeconomic Data and Applications Center (SEDAC), Columbia University, Palisades, NY, USA. Disponível em: http://sedac.ciesin.columbia.edu/plue/gpw/GPWdocumentation.pdf.

Dobson, J. E., E. A. Bright, P. R. Coleman, R. C. Durfee, B. A. Worley 2000, A Global Population Database for Estimating Population at Risk. Photogrammetric Engineering \& Remote Sensing 66(7): 849-857.

Dobson, J. E. 2002, War is God's Way of Teaching GIS. Proceedings of the Merrill Conference on Science at a Time of National Emergency. Disponível em http:/www.merrill.ku.edu/publications/2002whitepaper/dobson.html.

Freire, S. 2007, O projecto Demo Carto: modelação a alta resolução das distribuiçôes diurna e nocturna da população para planeamento e tomada de decisáo. Congresso Internacional sobre Planeamento Urbano - Avaliaçáo do Impacte na Saúde. Poster. Lisboa, Portugal, 23 Outubro 2007. 
Freire, S. 2008, Do dia para a noite: modelação em SIG da distribuição espacial e temporal da população com alta resolução para avaliação de risco e gestão de emergências. Actas do ESIG'2008-X Encontro de Utilizadores de Informação Geográfica. Oeiras, 14-16 de Maio, 2008, Págs. 233-246.

Freire, S. 2009, Modeling of Spatio-Temporal Distribution of Urban Population at High-Resolution - Value for Risk Assessment and Emergency Management. Actas do Joint Symposium of ICA Working Group on Cartography in Early Warning and Crises Management (CEWaCM) and JBGIS Geo-information for Disaster Management (Gi4DM). Praga, Janeiro 19-22, 2009, Págs. 176-183.

INE (Instituto Nacional de Estatística), 2001, Recenseamento Geral da População e da Habitação. Lisboa.

INE (Instituto Nacional de Estatística), 2003, Movimentos Pendulares e Organização do Território Metropolitano: Área Metropolitana de Lisboa e Área Metropolitana do Porto 1991-2001. Lisboa.

McPherson, T. N., e Brown, M. J., 2003, Estimating daytime and nighttime population distributions in U.S. cities for emergency response activities. Preprints: 84th AMS Annual Meeting. AMS, Seattle, WA, 10 pp.

Mennis, J., e Hultgren, T., 2006, Intelligent dasymetric mapping and its application to areal interpolation. Cartography and Geographic Information Science, 33(3), pp. 179-194.

Néry, F., P. Monterroso, A. Santos, J. Matos, 2007, Interpolação Zonal de Estatísticas Sócio-económicas. Actas V Conferência Nacional de Cartografia e Geodesia. Lisboa, Ed. Lidel, Págs. 89-99.

Sutton, P., Elvidge, C., Obremski, T., 2003, Building and evaluating models to estimate ambient population density. Photogrammetric Engineering \& Remote Sensing, 69(5), pp. 545-553. 